\title{
Heteroglossia, voicing and social categorisation
}

Madsen, Lian Malai

Published in:

Heteroglossia as Practice and Pedagogy

DOI:

10.1007/978-94-007-7856-6_3

Publication date:

2014

Document version

Early version, also known as pre-print

Citation for published version (APA):

Madsen, L. M. (2014). Heteroglossia, voicing and social categorisation. In A. Blackledge, \& A. Creese (Eds.), Heteroglossia as Practice and Pedagogy (pp. 41-58). Springer. https://doi.org/10.1007/978-94-007-7856-6_3 


\title{
Chapter 3
}

\section{Heteroglossia, voicing and social categorisation}

\author{
Lian Malai Madsen
}

\section{Introduction}

It is well documented in recent research on linguistic and cultural diversity that speakers in practice draw on their collective linguistic repertoires of resources to achieve their communicative aims in a given situation. We can observe how speakers use whatever linguistic resources are available to them when they communicate. Thereby their language use is not restricted by common associations of certain linguistic resources belonging to certain varieties or languages. Observations of speakers' combination of various linguistic resources in polylingual (Jørgensen et al. 2011) or heteroglossic (Bakhtin 1981, Bailey 2007) practices have led to recent re-examination of the restrictions and the ideological implications of traditional conceptions of 'language' or 'variety' in research as well as pedagogy (Blackledge and Creese 2010, Wei 2011), and it has been convincingly argued that such concepts are representations of particular language ideologies rather than of linguistic practice (Jørgensen 2010, Heller 2007, Blackledge and Creese 2010, Pennycook 2010).

Concurrently with the increasing diversification of diversity (Vertovec 2010) in today's globalised societies an interest for stylised, self-conscious, non-routine, double voiced linguistic practices (Bakhtin 1981, 1984, Coupland 2007, Rampton 2006) has grown within sociolinguistics (Jaspers 2010, Blommaert and Rampton 2011). The study of interactional stylisations appears particularly 
well tuned for attending to the sociolinguistic complexities of late modern settings, and stylised speech (and crossing) has played a significant part in the documentation of polylanguaging and heteroglossia (Jørgensen 2010, Rampton 1995, 2011, Møller 2009). Rampton (2009: 149) defines stylisations as instances of speech where speakers produce 'specially marked and often exaggerated representations of languages, dialects, and styles that lie outside their own habitual repertoire (at least as this is perceived within the situation at hand)'. The fact that these marked linguistic contributions build on relatively fragmented use of linguistic resources has been a key argument for the deconstruction of a view of languages as whole and bounded systems. Stylisations, however, are also examples of linguistic behaviour highlighting sociolinguistic reflexivity and thereby the evaluation of linguistic forms and their association with voices and values. Stylisations potentially contribute to breaking down imagined linguistic borders and imagined fixed relationships between signs, voices and speaker personae, but stylisations are achieved and recognised exactly because they build on some level of shared understanding of linguistic signs' (potential) indexical values based in the signs' historical and social relationships. So, on the one hand stylisation as a speech practice complicates the relationship between language, speaker and category belongings, and this is an important dimension for current ideological and theoretical discussions within sociolinguistic research. On the other hand, stylisations enhance speakers' language ideological constructions by flagging metapragmatic stereotypes and possibly forging new ones. Thereby the study of stylised strategically inauthentic language use (Coupland 2007) teaches us a great deal about how speakers still employ and bring about the constructs of 'styles', 'languages' or 'varieties' although through heteroglossic languaging. In addition the study of stylisations illuminates speakers' understandings and positionings in relation to sociolinguistic economies. As Jaspers (2010: 14) notes, stylised language use: 
...serve as an extremely fruitful starting point for investigating how utterances comment on the situation in which they are produced, how they are illustrative of participants' perceptions, and how these perceptions can be reconciled with, or rather challenge, inflect and/or reconfigure ideologized representations of language and social behaviour, and with what results

In this way, studying stylisations allows us to see the situated manufacturing of norms and to discover potential changes of sociolinguistic norms in the communities we study. In Blommaert and Rampton's (2011: 7) words they can make visible “the emergence of structure out of agency".

In this chapter, I discuss such an emergence (and change) of sociolinguistic structure through the study of interactional stylisations among Copenhagen adolescents. The data I discuss are from a collaborative linguistic ethnographic project. Rather than looking at stylisations as merely characteristic of contemporary urban heteroglossia with the aim of pointing out that the languaging of the young speakers is, indeed, complex, polylingual and multi-voiced, I will instead look into some of the specific stylisations among the adolescents in our study, their ideological implications and their relation to larger scale sociolinguistic developments. After a brief theoretical account of stylisation and enregisterment (Agha 2003) and an introduction to my data, I discuss some general aspects of the stylisations in our data, how particular stylised voices are achieved and what sociolinguistic building blocks are used as stylisation resources. Finally, I consider in more detail stylisations of speech corresponding to what the participants refer to as an 'integrated' way of speaking and their situated voicing of this way of speaking. I will argue that these interactional stylisations contribute to our understanding of ongoing enregisterment and to the interconnections 
between cultural and ethnic diversity and dimensions of hierarchical stratification in the contemporary sociolinguistic order(ing) among Copenhagen youth.

\section{Enregisterment, heteroglossia and stylisation}

Agha's theory of enregisterment $(2003,2005,2007)$ has been widely employed and discussed within the past years of sociolinguistic research (Johnstone et al. 2006, Johnstone 2009, Rampton 2011, Cambell-Kibler 2012, Eckert 2008, Madsen et al. 2010, Frekko 2009). The concept of enregisterment appeals to contemporary sociolinguistics with its emphasis on "processes and practices whereby performable signs become recognized (and regrouped) as belonging to distinct, differentially valorized semiotic registers by a population" (Agha 2007: 81). The theory of enregisterment accounts for the processes through which linguistic styles (or in Agha's terms registers) are constructed and take into consideration metapragmatic activities on various levels ranging from widely circulating media stereotypes to local speaker practices. The focus on styles as created through repeated semiotic activities combines well with the view of linguistic codes as socio-cultural and ideological constructs as well as with an interest in the relation between wider sociolinguistic processes and situated agency.

From an enregisterment perspective, speakers' interactional use of different linguistic forms (re)creates the stereotypic indexical values of the used forms. The ascription of values to linguistic forms can be more or less explicit. In our study in Copenhagen, for instance, discussions of 'ways of speaking' in interviews are examples of explicit evaluative linguistic data. Stylisations occurring during these metalinguistic discussions tend to serve as (often exaggerated) demonstrations of enregistered styles and emphasise associated stereotypic indexical values. Stylisations occurring in peer interactions can of course serve a variety of local communicative purposes. Still, they are 
examples of linguistic behaviour highlighting the evaluation of linguistic forms and their associated values. In this sense all stylisations are relatively explicit metalinguistic activities. Agha (2005: 38). notes that encounters with registers are:

encounters in which individuals establish forms of footing and alignment with voices indexed by speech and thus with social types of persons, real or imagined, whose voices they take them to be

In situated performances of stylisations, speakers align in various ways with the voices taken to be indexed by the registers they use. These alignments are part and parcel of social categorisation. Stylisations are linguistic activities that put on display the simultaneously unique and sociostructural qualities of language forms. Bakhtin describes language in use as entailing two forces operating at once: A centripetal force drawing features, structures, and norms towards a central unified point, and a centrifugal force working in the opposite direction drawing away from the central unified point towards variation in all directions (Bakhtin 1981: 667-68). This is to be understood at the level of linguistic processes at large, centripetal forces resulting in language standardisation (and register formation in Agha's sense), and centrifugal forces resulting in language variation, but the forces also work within every single utterance: "Every concrete utterance of a speaking subject serves as a point where centrifugal as well as centripetal forces are brought to bear" (Bakhtin 1981: 668).

The notion of heteroglossia emphasises the centrifugal forces. Heteroglossia is, according to Andersen (2010: 17), a concept created by the translators of Bakthin's work to cover the three concepts of rasnoretjije (diversity in 'speechness'), rasnojasytjije (diversity in 'languageness'), and 
rasnogolositsa (diversity in 'voicedness'). As a cover term for these aspects of linguistic diversity heteroglossia describes how language use involves various socio-ideological languages, codes, and voices. The presence of different speech and speaking positions within the utterance is what Bakhtin refers to as double voicing. While most linguistic practice should be considered double voiced, some employments of others' voices are hardly distinguishable from the speaker's own voice (towards uni-directional, Bakhtin 1984: 199), and other usages of others' voices are more clearly separable from the speaker's own, as the use involves intentions different from the intention of the original voice (towards vari-directional, Bakhtin 1984: 193). Hence, a stylisation can be described as noticeable double voicing. According to Bakhtin a stylisation involves "an artistic image of another's language" (Bakhtin 1981: 362). Two basic elements are crucial, then, to the identification of stylisations: 1) They are artistically marked linguistic productions, and 2) they involve associations with languages or voices of another (different from the speaker) (Rampton 2006: 225, Bakhtin 1981: 362).

Rampton (2009: 149) further characterises a stylisation as:

[...] reflexive communicative action in which speakers produce specially marked and often exaggerated representations of languages, dialects, and styles that lie outside their own habitual repertoire (at least as this is perceived within the situation at hand)

We notice a linguistic production as stylised in a given situation because it in one way or another stands out compared to a speaker's general linguistic behaviour as it is known to us as linguistic ethnographers or interlocutors in a given interaction. Stylisations are perceived in relation to assumed expectations of regular speaker behaviour, regular range of features, regular voices, and 
regular users of voices. Yet, it is worth noting that stylisation as such is not an exceptional practice in interactions among (perhaps in particular, contemporary young) speakers. Consequently, stylisations sometimes do not at all result in any observable reactions among other participants although the analyst might notice a stylised voice (as also Rampton 2006: 225 notes). In addition, as we shall see, the stylised performance of the participants in our study suggests that not all stylisations can be described as representations of widely enregistered 'sets of features'. Some stylisations are representations of another's voice and a particular ideological speaking position, but not necessarily another's 'language', 'dialect' or 'style'. Whether or not I consider a stretch of talk a stylisation is informed by my familiarity with the participants in our study. My experience as speakers with knowledge of available linguistic resources and their social connotations in the contexts of Copenhagen further helps determine whether an utterance should be considered stylised or not. Finally, considerations of the situated interactional context, the co-participants' responses and the co-occurring linguistic features in an utterance has informed my analysis of stylised speech.

\section{Empirical basis}

The stylisations I discuss are from data collected as part of a linguistic ethnographic project in Copenhagen (The “Amager Project”, Madsen et.al 2010, Madsen 2011, Møller and Jørgensen 2011, $\operatorname{Ag} 2010$, Stæhr 2010). The overall focus of our research is to understand how language patterns and language norms are acquired, developed, and used in various everyday contexts. Most of the participants in our study have a linguistic minority background and they live in a highly diverse area of the Danish capital. Since 2009 we have been following two grade school classes in a Copenhagen public school from the $7^{\text {th }}$ to the $9^{\text {th }}$ grade (the students are $13-15$ years old). We have carried out team ethnography and collected a wide range of linguistic data in various contexts. The data include field diaries, audio recordings during classes and breaks in school, written essays, 
facebook activities, and various school related documents. We have collected self-initiated recordings in school and leisure settings such as the youth club, sports clubs, in the local neighbourhood, at concerts and in the participants' homes. In addition we have interviewed all participants in groups and individually (as well as teachers, parents, and club workers). The present discussion builds on 31 hours of the audio recordings in various contexts and includes group interviews as well as recordings in and out of school.

\section{Sociolinguistic context and metalinguistic accounts}

Before we turn to the data, some contextual information on the sociolinguistics of Danish as well as the sociolinguistic awareness of the participants should provide a useful entry point for looking at the stylisation practices of the Copenhagen adolescents. Briefly described, the overall sociolinguistic development in Denmark is characterised by strong linguistic homogenisation and a dominating standard ideology (Kristiansen and Jørgensen 2003, Pedersen 2009). Kristiansen (2009: 168) suggests that Danish today is possibly more homogeneous than any other language with millions of speakers. Currently, there is very little grammatical variation within speech observed around the country. Local 'accents' are signified primarily by prosodic colouring, and the existing nationwide variation in segmental phonetics is strongly dominated by developments and spread from Copenhagen speech (Kristensen 2003, Kristiansen 2009). However, as recent studies of interaction, language attitudes, and language ideologies show (Madsen 2011, Jørgensen 2010, Møller 2009, Maegaard 2007, Quist 2005), this does not mean that young speakers in the Copenhagen area grow up without ideas about linguistic differences and their related social values. The dialectal and the traditional sociolectal differences might be close to extinct judging by the number of varying linguistic features, but only a few linguistic signs are necessary to bring out the wider social connotations of particular ways of speaking. Subtle features like prosodic colouring 
can still have the strong effects of signalling, for instance, a rural or an urban persona. However, the question is whether traditional sociolectal and dialectal features might not be as readily available and relevant resources of social distinction to contemporary Copenhagen youth.

Our study of explicit metalinguistic accounts from our participants hints at a sociolinguistic transformation taking place among contemporary youth (Madsen et al. 2010, Madsen 2011, Møller and Jørgensen 2011). During interviews with the participants in our study in the first year of our collection period they introduced labels for two ways of speaking that differ from what they refer to as "normal". One was "integreret" (integrated) and the other was referred to with varying labels: predominantly "gadesprog” (street language), but also "perkersprog" (equivalent to paki language) or "slang" (slang). "Perker" is originally a derogatory term used about immigrants equivalent to 'paki' or 'nigger'. In in-group use, however, the term refers to a social category defined by ethnic minority status (in relation to the Danish majority society) across various ethnicities. Moreover, in local in-group use "perker" also invokes values of toughness and street-credibility (Madsen 2008: 214). In spite of the different naming practices, there was general agreement in the reports on characteristic features of this way of speaking. Characteristic features of 'street language', according to the participants, include slang, swearing, affricated and palatalised t-pronunciation, poly-lingual 'mixing' practices, what they refer to as a 'strange accent' and linguistic creativity (linguistic innovations). This way of speaking is associated with the stereotypic indexical values of toughness, masculinity, youth, pan-ethnic minority 'street' culture and academic non-prestige. In contrast, the participants characterise 'integrated' speech by features of distinct pronunciation, abstract and academic vocabulary, high pitch, quiet and calm attitude and ritual politeness phrases. This way of speaking is associated with up-scale culture, sophistication, authority, emotional control and aversion to rudeness, academic skills, politeness and respect. Thus, in the values and 
privileges it evokes, 'integrated' seems to be undergoing enregisterment as a conservative standard code, and street-language is enregistered partly in opposition to this (see detailed analysis in Madsen 2011, 2013). Yet, the label for the more conservative speech style of 'integrated' (in Danish public predominantly used about satisfactorily adapted immigrants) as well as its oppositional relation to the contemporary urban vernacular speech (containing features indexing cultural and linguistic diversity) also bring about a dimension of minority/majority relations that has not previously been included in the stereotypical associations related to a conservative standard register. In addition, the socio-hierarchical dimension of contemporary youth speech has perhaps been overlooked by recent sociolinguistics.

Of course, there can be significant differences between speakers' reports about language use and their actual linguistic practice. The accounts summarised here provide important insights into the speakers' ideas about linguistic stereotypes, but the study of how linguistic stereotypes are brought into use for situated pragmatic functions in particular interactional contexts may add to and possibly alter the picture (Rampton 2006 and Jaspers 2011 are good examples of this). We shall now have a look at how the stylisation practices, overall, as well as a specific type of stylisation relate to these sociolinguistic tendencies.

\section{Stylisations, sociolinguistic features and enregisterment}

An overview of the stylisations, based on the 31 hours of recordings, teaches us that the participants during these recordings produce utterances containing stylised speech 253 times. On average, the adolescents use stylisations approximately every 7-8 minutes, and stylisation is clearly a regular linguistic practice among our participants. Of course the stylisations do not occur as evenly spread in the data, rather they appear to come in clusters and one stylisation is often followed by others. 
There are no striking differences in the frequency of stylisations as such between different communicative contexts. Stylisations occur in interviews, during classes as well during breaks and leisure activities, and they are directed at researchers and teachers as well as peers. However, during focussed teacher-led educational activities, stylised utterances are rare (and some teachers practice and regularly achieve this kind of focussed interaction).

The participants' more unmarked speech is characterised by frequent use of the new phonetic features associated with a contemporary urban youth style (described in Maegaard 2007, see also Madsen 2012, Madsen et al. 2010) as well as a characteristic prosody of this style (Pharao and Hansen 2006, Madsen 2012). In general, they employ the features they describe as associated with 'street language' in their regular peer interactions (slang, mixing etc.), and they also routinely produce stretches of speech containing mostly young Copenhagen features where features of slang and mixing, for instance, are left out and the use of non-standard pronunciation features is reduced.

In their marked and stylised linguistic practices the participants bring about a diverse range of speaker personae from 'elderly lady' to 'tough black rapper' or 'adult immigrant', and they employ a variety of linguistic resources. Some of the linguistic resources they use are widely enregistered as indexical of specific speech styles. Examples of these kinds of widely recognisable resources from our data are pronunciation features associated with stylised Asian English, such as combinations of even stress on every syllable, shortening of long vowels and change of diphthongs to monophthongs (see Rampton 1995: 68). Other features achieve their indexicality only in the particular interactional context because of their co-occurrence with certain other linguistic resources and certain pragmatic functions. A particular feature might potentially relate to various metapragmatic stereotypes, but the contextual use suggests emphasis on one (or some) over others. In our data we find, for instance, 
exaggerated high pitch and shrieky voice used for different stylisations. Combined with ritual politeness phrases these features contribute in some interactional contexts to stylising an 'integrated' and 'posh' persona. Yet, in other cases the exaggerated high pitch and the shrieky voice are, for example, combined with ridiculing repetitions of a girls' call for help or someone's scream of fear (in reaction to a horror movie clip). In these contexts similar linguistic features contribute to indexing weakness and hyper femininity rather than poshness. We also see examples of different potential indexicalities of a specific pronunciation feature that the participants are highly metalinguistically aware of. Affricated and palatalised t-pronunciation ([tj] instead of standard [t], one of the new pronunciations (see Maegaard 2007: 68), is a feature commonly used in the adolescents' routine speech, but also a feature explicitly flagged in exaggerated verbal stylisations or in spelling practices, for instance, on facebook (' $t \mathrm{j}$ ' for standard ' $\mathrm{t}$ '). This t-pronunciation is, however, in some cases employed as indexical of specific ethnically Turkish-marked pronunciation of Danish and in other cases as a marker of the cross-ethnic 'street language' (Madsen et al. 2010, Madsen 2011).

Hence, the stylisations in our data draw on linguistic resources enregistered to different degrees. Some involve wide ranging enregistered styles (Agha 2005, 2007) recognised by a relatively large population, others are locally bound and involve linguistic features of more ambiguous indexicality. We can describe the stylisations as working on different scale levels between more locally context bound at one end and more widely enregistered in the other. In fact, the most common type of stylisation in our data is specific parodying stylisations of other participants' or teachers' speech. These stylisations are of course closely tied to the local communicative context in which they occur and their situational effect is less dependent on the specific linguistic features employed. Yet, the choice of the linguistic features used in these locally situated parodies is not completely arbitrary, 
but consistent with the indexical field (Eckert 2008) of the features used. For instance, stylisations in our data involving 'girlish' or 'childish' qualities involve pitch raise, whereas a lower pitch is used, for instance, to signal 'adult authoritative' and 'dull' voices.

The different types of stylisations are not considered equally significant to wider sociolinguistic processes. Naturally, the more broadly enregistered kind of stylisation is of more interest to studies of general processes of sociolinguistic categorisation. In our data the next most common type of stylisation involve such widely enregistered sets of features, namely those related to ethno-linguistic stereotypes. Out of the 253 cases of stylisations I have identified in this material, 53 bring about associations of ethnicity or nationality (admittedly very different ones). The adolescents employ exaggerations of features associated with Danish spoken with Pakistani accent (2), English spoken with Pakistani accent (4), stylised Urdu (2), Danish as spoken by Turks (2) American accented English and English spoken by Africans (3), and they play with linguistic fragments associated with Icelandic (2), Filipino (1), Chinese (1), Russian (3), Arabic (16), French (5), German (4) and Spanish (8), and in addition they stylise cross-ethnic 'immigrant/learner' Danish and English. In comparison to the varied range of ethno-linguistic stereotypes employed in their stylisation practices, the participants rarely stylise dialectal, place-related speech. There are 3 cases of a broad use of Jutlandic-coloured prosody and pronunciation. Also there are no stylisations that can be characterised as traditional Low- or High Copenhagen speech (though the examples I discuss in section 6 include a few vowel pronunciations traditionally involving 'High' connotations). This overall picture of stylisation practices, in fact, corresponds well to the sociolinguistic tendencies described in recent Danish research of dialectal and sociolectal differences diminishing (Kristiansen and Jørgensen 2003) and ethnic differences becoming increasingly significant (Quist 2005, Maegaard 2007). This seems to suggest that socio-cultural differences are not marked by linguistic 
resources among the adolescents. However, the metalinguistic reports of the participants in our study did point to the relevance of social stratification in their understanding of stylistic differences, and, of course, there is a leap between the linguistic material used and the social categories indexed by (stylised) speech. These adolescents clearly do not bring about societal hierarchical relations through the traditional linguistic means of distinction of traditional High and Low features, but the third most common type of stylisations in these recordings shows that they did bring about such relations in a different way, and now I turn to some detailed examples of that.

\section{Relations of authority and 'integrated' stylisations}

I will discuss four examples of similar stylisations involving three different speakers in three different interactional sequences. I argue that these stylisations can be characterised as 'integrated' speech (in the participants' understanding). Yet, 'integrated' speech is not an example of a widely enregistered and well documented style, it could be placed somewhere in between locally bound and widely enregistered. Therefore, I will stay close to the level of local practice in these interactional sequences before I compare the examples to the metalinguistic descriptions of our participants.

The excerpts 1.a and 1.b are from one of Bashaar's (Bas) recordings during a Danish lesson in grade 8 . In the beginning of the lesson the teacher tends to some practical issues regarding a school party and to some changes in the usual week plan. She informs the class that the school staff has decided to cancel the party because of too few responses from the students' families, and Bashaar has loudly expressed his disapproval of this decision (not without awareness of his classmates being entertained by this). During this recording period the class participated in a rap workshop. The aim of the workshop was to learn about poetry through practicing rap music with young professional 
rappers and producers. The class had to stay longer than usual one day because of this workshop (it involved performance and recording of their own rap song). Just prior to this sequence, the teacher, Susanne (Sus) has complained about the students not passing on information about school activities at home and not returning acceptance forms from their parents (in this case a signed form allowing their child to be recorded during the rap workshop). Bashaar has been mentioned as one of those who still have not returned the form and the teacher has claimed that students who have not handed in the form will not be allowed to participate in the recording. To this warning Bashaar has replied “jo selvfølgelig” (yes of course). So, aspects of criticism from the teacher as well as the teacher's power to sanction unsatisfactory behaviour (by cancelling parties and not allowing pupils to participate in certain activities) is at play in this stretch of conversation. At the same time Bashaar's behaviour in the class (in general) as an entertainer and provocateur plays a significant part. In the beginning of this sequence, the teacher explains that they will get to leave earlier another day because they are asked to stay longer on the day of the recordings. The stylised utterances in focus are marked by arrows on the right side of the translation column, and pronunciations noticeably differing from Bashaar's usual contemporary urban speech style, are highlighted in bold.

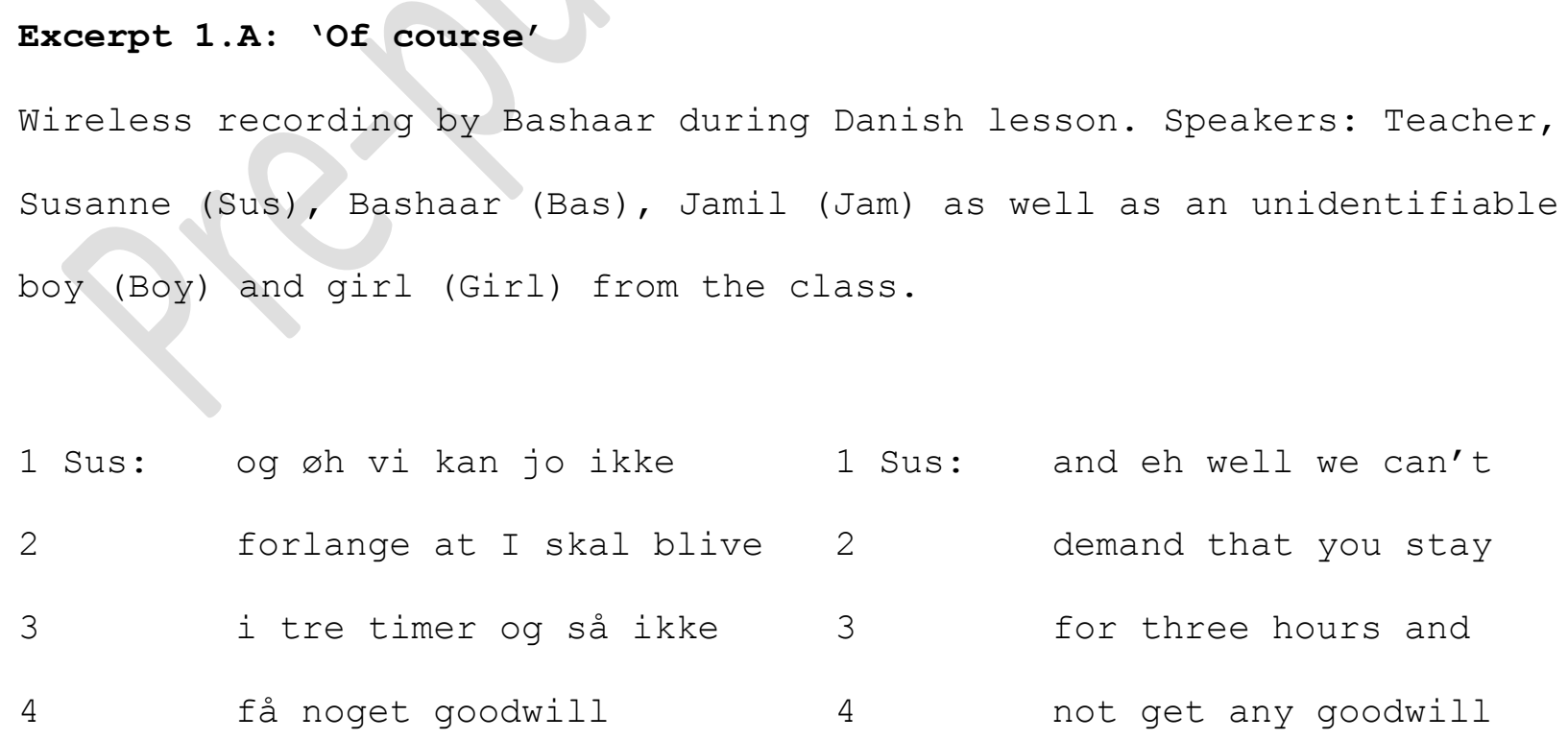




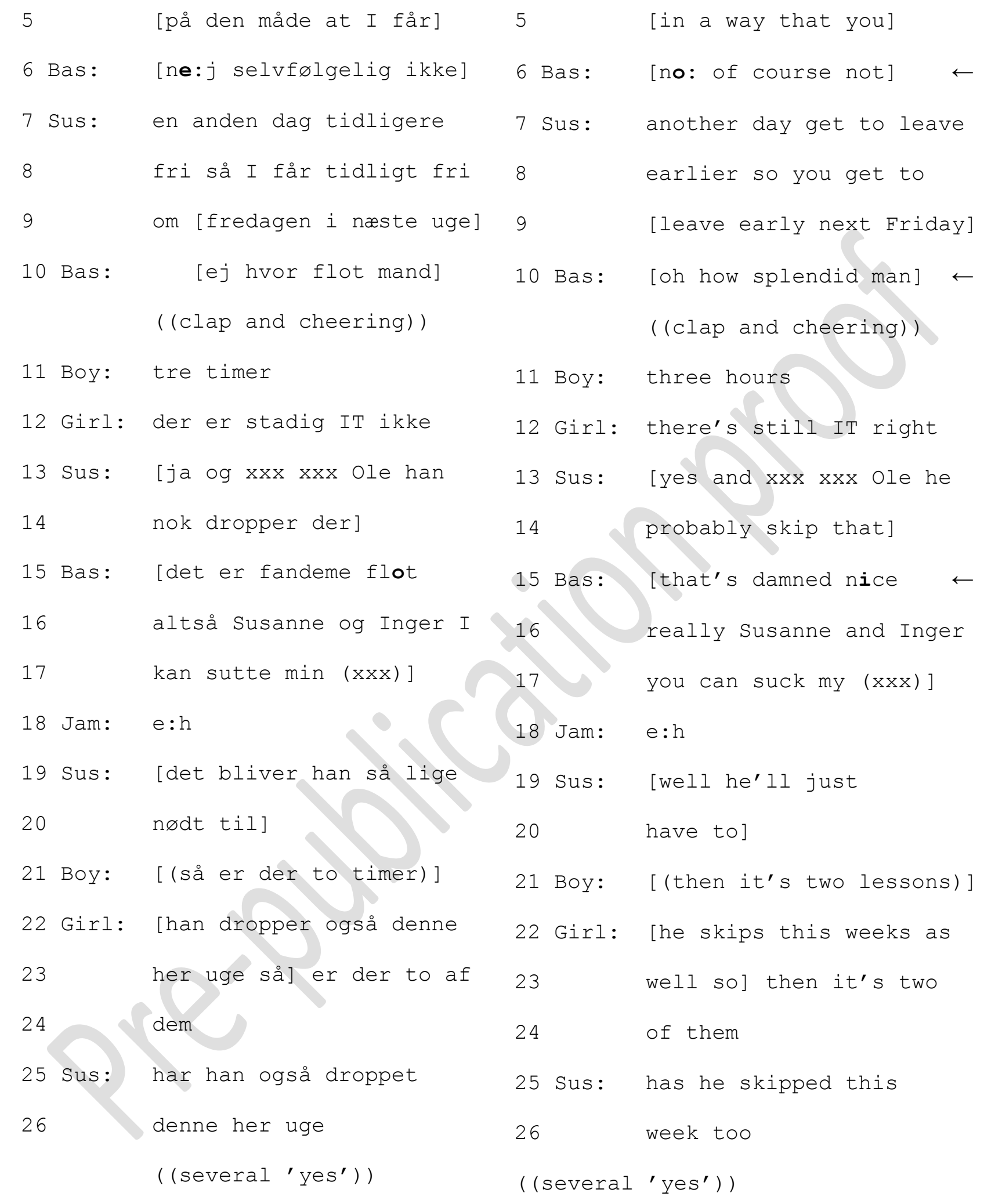


Bashaar's contributions in line 6,10 and 15-17 are interesting as stylisations that are doubled voiced in more than one sense. They combine linguistic and communicative resources that point in the direction of different speaker personae. Partly because of this they leave the impression of a varidirectional (Bakthin 1981) voicing of enthusiasm (line 6 and 10) as well as complaint (line 15-17). The utterances function as comments on the information and explanations given by the teacher, but they are not direct contributions to the official classroom discourse. Rather they are directed at the classmates in the immediate surrounding. They are spoken in overlap with the teacher's speech and not in a loud voice. On the surface the utterances in line 6 and 10 are expressions of agreement and approval. In line 6 , the initial prolongation and a relatively more fronted and unrounded pronunciation of the vowel in "nej" (no) (compared to Bahsaar's more frequent pronunciation of 'no') signals inauthenticity. This vowel pronunciation is stereotypically associated with conservative standard speech. Here, it is combined with the expression 'of course' which Bashaar has used in a similar utterance four minutes earlier and, as we shall see in the next excerpt, he repeats twice more within one minute. This recycling and repeating of the expression of agreement contributes to the impression of exaggerated obedience. The utterance in line 6 can be considered a vari-directional stylisation of an obedient and enthusiastic student voice indexed by relatively subtle linguistic features of a conservative standard pronunciation combined with a polite expression of agreement. The utterance in line 10 is partly a similar stylisation. It expresses enthusiastic approval and achieves its marked character predominantly through the choice of vocabulary: "ej hvor flot" (oh how splendid). Yet, this expression of approval with rather conservative and up-scale cultural connotations is combined with a slang expression "mand" (man) frequently used in the adolescents' casual speech. In this way the utterance is not only double voiced in the sense that it is another's voice the speaker uses, but it is also on a linguistic level a combination of several voices. The combination as such further contributes to the inauthentic impression. This is neither an authentic 
conservative voice nor an authentic contemporary youth voice. The same kinds of voices appear in the last utterance (line 15-17). Here the features of the swearing "fandeme" (damned) and the "I kan sutte min $x x x$ " (you can suck my xxx), whatever it is he suggests they can suck (unclear from the recording), signals casual youth speech. Yet, the "flot" (splendid) is pronounced with slightly fronted and unrounded vowel connoting conservative standard speech. So through this combination of linguistic and pragmatic features, Bashaar manages to express the opposite of agreement and approval in reaction to a teacher's criticism and sanctioning to the entertainment of the classmates in his immediate surrounding.

The next excerpt is the immediate continuation of 1.a. Here Bashaar brings his performance to the front stage of the class room and to the teacher's attention. Towards the end of sequence 1.a, the teacher has in cooperation with some of the other students established that the changes to the usual educational schedule involve cancellation of the IT (information technology) class the following week. This led a girl in (line 22) to remark that the IT teacher (Ole) has cancelled the IT class the current week too.

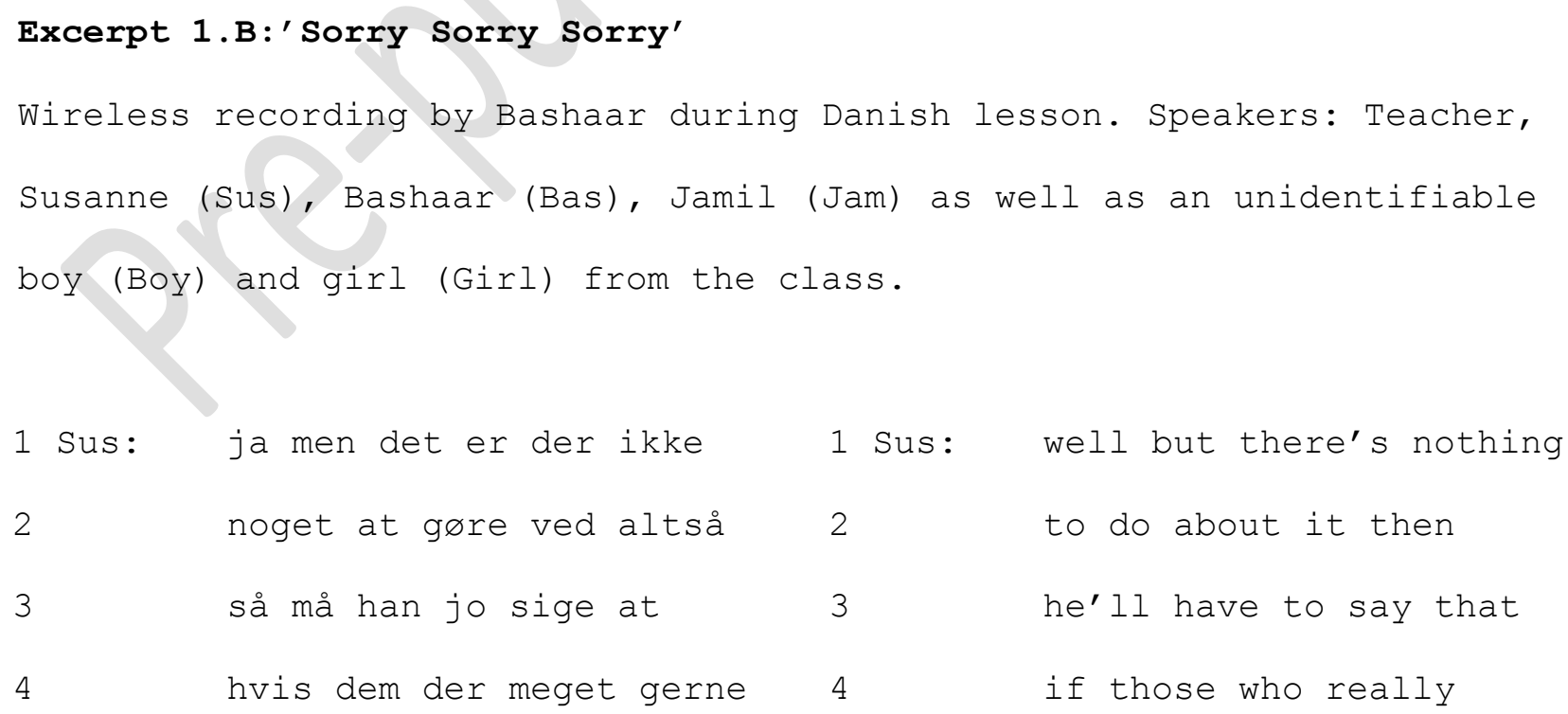




\begin{tabular}{|c|c|c|c|c|}
\hline \multicolumn{2}{|l|}{5} & vil have IT så må jeg jo & 5 & want to have IT then \\
\hline 6 & & komme tilbage der hvis & 6 & I'll have to come back \\
\hline 7 & & man vil det & 7 & if one wants to \\
\hline 81 & Bas: & HAR HAN OGSÅ DROPPET DET & 8 Bas: & HAS HE SKIPPED IT THIS \\
\hline 9 & & DENNE HER UGE? & 9 & WEEK AS WELL? \\
\hline 10 & Girl: & denne her uge [ja] & 10 Girl: & this week [yes] \\
\hline 11 & Boy: & {$[j a] \quad x x x$} & 11 Boy: & [yes] $\mathrm{xxx}$ \\
\hline 12 & Bas: & ej det er KRAFTEDEME & 12 Bas: & no that's FUCKING \\
\hline 13 & & også ham der mand & 13 & him again man \\
\hline & & ( (bangs the table, & & ( (bangs the table, \\
\hline & & several laugh)) & & several laugh)) \\
\hline 14 & Bas: & UNDSKYLD UNDSKYLD UNDSKYLD & 14 & SORRY SORRY SORRY \\
\hline 15 & & UNDSKYLD UN UNDSKYLD & & SORRY SO SORRY \\
\hline 16 & & [UNDSKYLD UNDSKYLD] & & {$[S O R R Y \quad S O R R Y]$} \\
\hline 17 & Sus : & [tal lige ordentligt] & 17 Sus: & [speak properly] \\
\hline 18 & Girl: & [ (så siger du kraftedeme)] & 18 Girl: & [(then you say fucking)] \\
\hline 19 & Bas: & [UNDSKYLD UNDSKYLD ] (.) & 19 Bas: & {$[$ SORRY SORRY $] \quad()$.} \\
\hline 20 & & undskyld undskyld & 20 & sorry sorry \\
\hline & & $(($ laughter $))$ & & $(($ laughter $))$ \\
\hline 21 & Sus: & der er en grund til at ole & 21 Sus: & there's a reason why ole \\
\hline 22 & & han har droppet det han er & 22 & he has skipped it he is \\
\hline 23 & & på noget uddannelse det & 23 & on some education there \\
\hline 24 & & kan være der er en bestemt & 24 & might be a certain \\
\hline 25 & & grund til at han skal & 25 & reason why he has to do \\
\hline 26 & & noget med den uddannelse i & 26 & something with the \\
\hline 27 & & dag så han ikke kan komme & 27 & education today so he \\
\hline
\end{tabular}




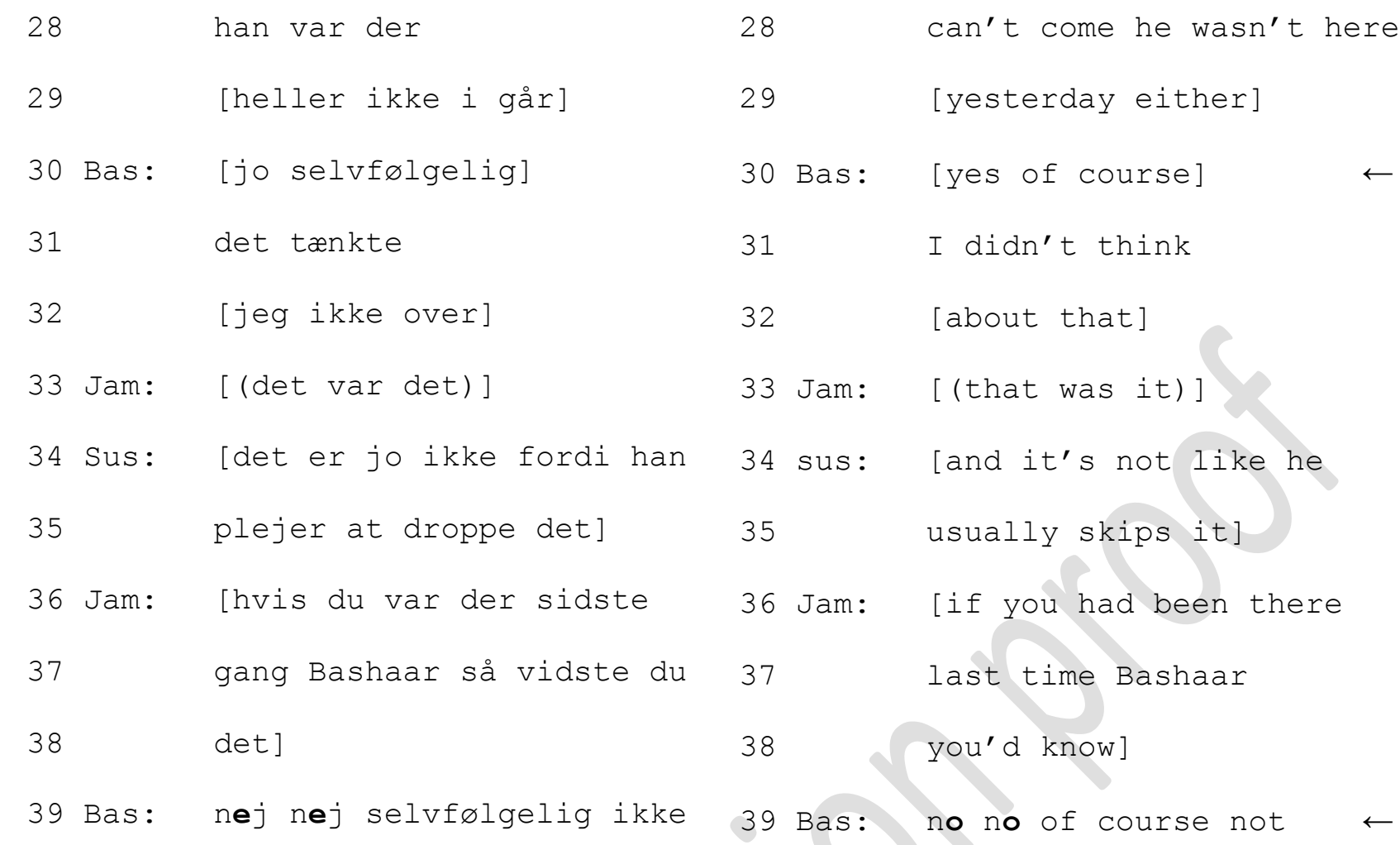

After Susanne's explanation of the cancellation of the IT class (line 1-7), Bashaar loudly asks a clarifying question and receives confirmation from some of the other students that the class is cancelled both weeks. The teacher has stopped talking and Bashaar has the attention of the class when he, in line $12-13$, reacts to this information with a clear expression of dissatisfaction. The complaint about the IT-teacher is marked by a strong swear word spoken louder than the surrounding words and thereby emphasised. In addition, the utterance is accompanied with a bang on the table which contributes an element of aggression. The utterance is reacted to with laughter from the other students. Immediately after the complaint, not leaving room for the teacher to respond, Bashaar continues with an apology, that consists of no less than 11.5 'sorry's ("undskyld", line 14-20), repeated without pauses and in a high volume. The teacher's corrective reaction to the loud swearing 'speak properly' (line 17) is nearly drowned in 'sorry's. In this sequence we see how Bashaar first claims the classroom floor with norm-breaking linguistic and social behaviour, in 
aggressive language he complains about a teacher in front of another teacher, and then he performs a highly exaggerated excuse (in volume and quantity). The exaggeration leaves the impression of insincerity and a voice of an obedient student is, again, vari-directionally stylised. Bashaar continues this stylisation in line 30 and 31 in response to the teacher's further explanation of her colleagues' reasons for cancelling the IT class. These utterances are marked by the repetitions of 'of course' and by the more fronted and unrounded pronunciation of the vowel in "nej" (no).

In excerpt 2, we see a short similar example of inauthentic expression of agreement with the teacher in response to criticism. Again, this stylisation is achieved through the use of few and subtle linguistic recourses. The teacher complains that they spend a lot of time on non-curriculum issues and practicalities in the beginning of the class, and she requests that they leave their coats outside (which they were supposed to do before the class started).

\section{Excerpt 2: 'Yes Inger'}

Wireless recording by Mahmoud during a Danish lesson. Speakers: teacher, Inger (Ing) and Mahmoud (Mah)

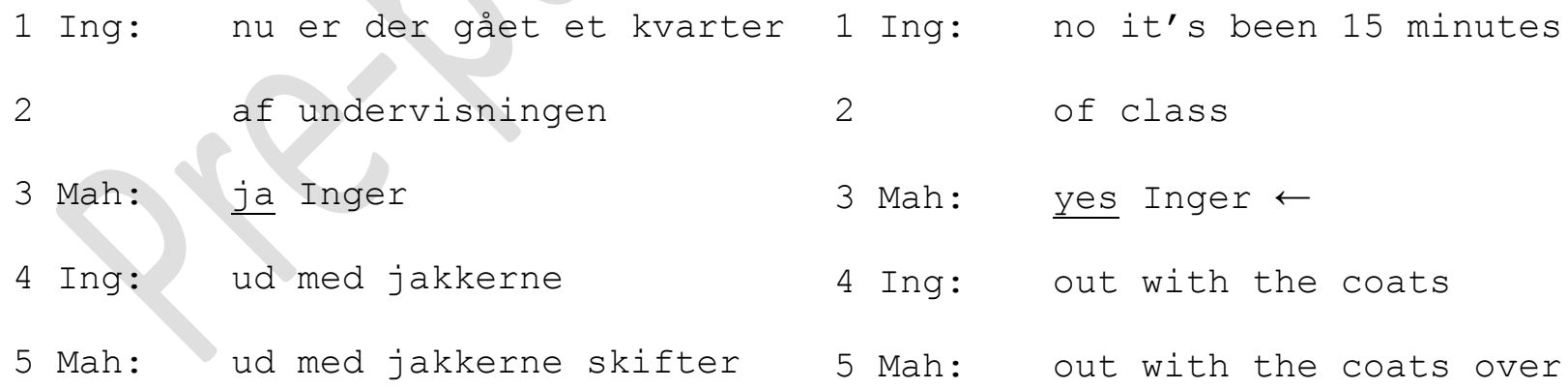

Inger remarks that they have now wasted 15 minutes of the class, and Mahmoud responds to this with a noticeably emphatic stress and distinct pronunciation of 'yes' followed by the teacher's 
name. These simple features are enough to leave the impression of a stylised voice and inauthentic agreement. In line 5, Mahmoud repeats the request of the teacher to take their coats out, as if supporting her, but then he adds "skifter" (over), as if communicating to someone through a handheld transceiver. This last addition contextualises the contribution as non-serious and playful. In addition, it brings into focus the recording device and thereby the issue of being researched. Thus, this example in fact combines the two types of interactional contexts where we find this kind of stylisation used, namely, in situations where issues of being corrected by teachers or other adults or issues of being investigated by researchers are at stake.

In the final example, the dimension of being researched is brought about playfully through a staged interview. A member of our research team, Andreas, has asked Isaam if he can record some freestyle rap with him. So, an academic from the university has talked him into performing some freestyle in the schoolyard. Isaam, though, is the one in control of the recorder. In this sequence he records a pretend interview. Musad acts as the interviewer asking about Isaam's thoughts about rap.

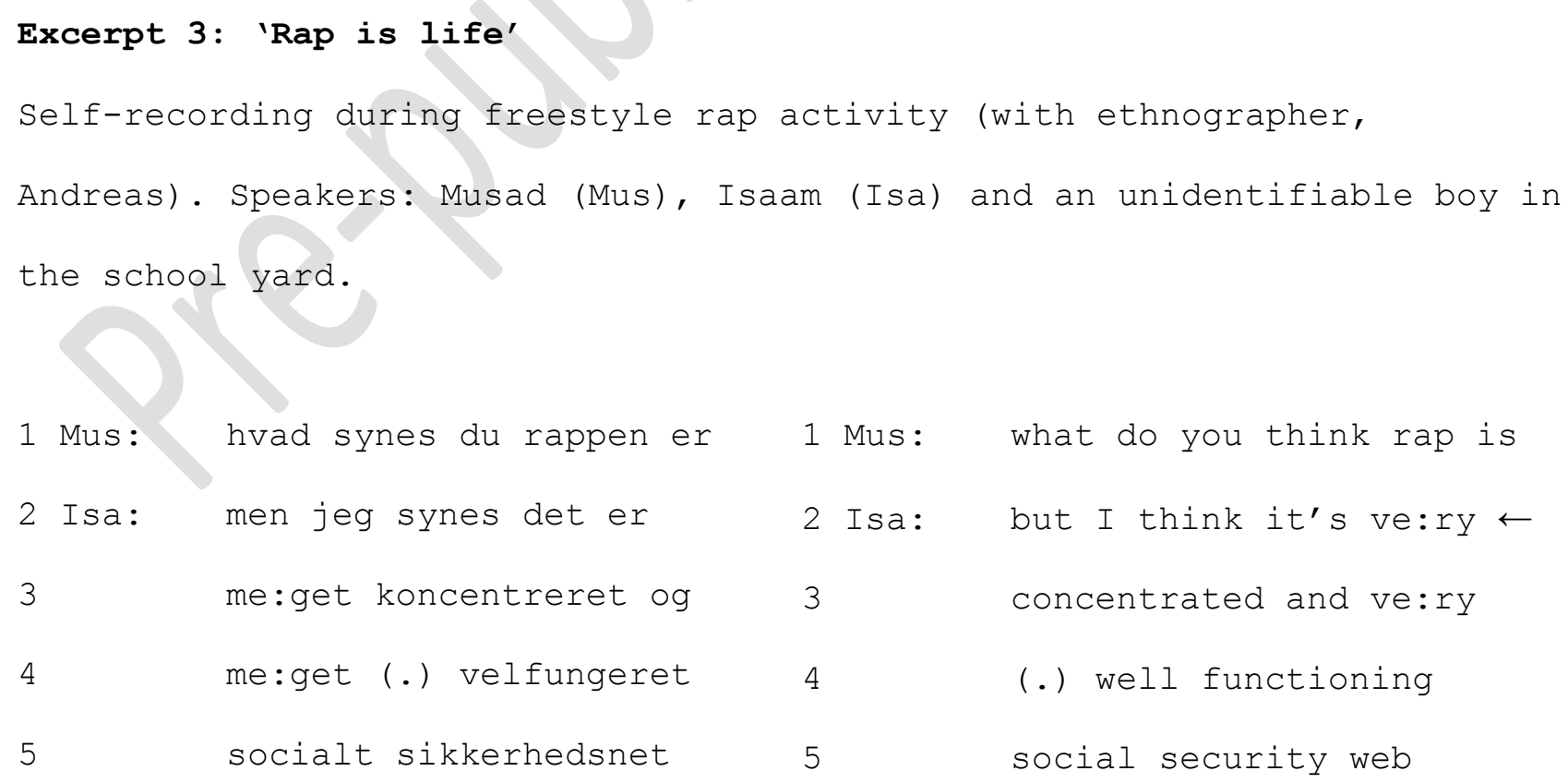




\begin{tabular}{|c|c|c|c|c|}
\hline 6 & & fordi [rappen] & 6 & because [the rap] \\
\hline 71 & Mus: & [pas på] (du ikke & 7 Mus: & [watch out] (you \\
\hline 8 & & sutter min finger af) & 8 & don't suck my finger off) \\
\hline 9 & Isa: & fordi fordi rappen & 9 Isa: & because because rap $\leftarrow$ \\
\hline 10 & & $(0.2)$ rappen & 10 & $(0.2) \mathrm{rap}$ \\
\hline 11 & Mus: & ja rappen $[\mathrm{xxx}]$ & 11 Mus: & yes rap $[x x x]$ \\
\hline 12 & Isa: & [rappen] det & 12 Isa: & $i: t^{\prime} s \leftarrow$ \\
\hline 13 & & e:r livet og livet det & 13 & life and \\
\hline 14 & & er tærte & 14 & is pie \\
\hline 15 & Boy: & hold nu kæft (idiot) & $15 \mathrm{BOI}$ & shut up (idiot) \\
\hline 16 & Mus: & hvad siger du der er & 16 Mus & what do you say there's \\
\hline 17 & & nogle der siger at de & 17 & who say that they \\
\hline 18 & & har ikke noget liv dem & & haven't got a life \\
\hline 19 & & der rapper hvad sige & & those who rap \\
\hline 20 & & du til det & 20 & what do you to that \\
\hline 21 & Isa: & jeg siger de sh & 21 Isa: & I say they should go home \\
\hline 22 & & og kneppe deres mor så & 22 & and fuck their mum then \\
\hline 23 & & kan de se hvad et liv er & 23 & they can see what life is \\
\hline
\end{tabular}

Isaam's response to Musad's question (line 2-6, 9-10 and 12-14) is predominantly marked by the choice of vocabulary in his description of rap. The expressions 'concentrated', 'well functioning', and 'social security web' are not regularly used by Isaam and here they are combined with prolongation of the vowels in "meget" (very) as well pauses and repetitions (line 6, 9, 10 and 12). This combination of features leaves the impression of a thoughtful sophisticated, academic voice presenting the meaning of rap to the interviewer. In line 12-14 Isaam becomes almost philosophical 
when he describes rap as "livet" (life) and the continuation "livet er tærte" (life is pie) of course emphasises the playfulness of the sequence. In this utterance 'life' is pronounced with marked exaggerated distinct pronunciation with a final aspirated plosive (more distinct than a conservative standard near pronunciation). The reference to 'well functioning social security web' also seems to connote socio-political discourses of societal integration that are not unfamiliar to participants, like Isaam, in the local youth club and in council supported integration-initiatives through rap music, but it would extent the scope of this paper to discuss this aspect in detail. Isaam's performance here is, indeed, reacted to as inauthentic and he is asked to 'shut up' (line 15), but Musad teasingly continues to play along with the interview role play and asks Isaam to comment on the opinion of rappers not having a life. Issam in his response to that switches to a more vernacular voice, as he tells those of that opinion to 'go home and fuck their mum' (line 21-22).

\section{Conclusion}

The stylisations I have discussed on the basis of these four data excerpts have in common that they are achieved through

1) a lack of features associated with the contemporary urban speech style sometimes described by the speakers as 'street language' and instead a use of relatively unmarked young Copenhagen pronunciations

2) a combination of selected extra distinct or marked conservative pronunciations with exaggerated expressions of agreement, enthusiasm or politeness and vocabulary indexing sophistication/academic reflection.

In other interactional examples from our data (that I have not treated in detail here), similar features were occasionally also combined with a pronunciation characterised by exaggerated high pitch and 
a shrieky voice. The stylisations involve often rather subtlety signalled, but still noticeable inauthenticity, and it is achieved as much through semantic and pragmatic features as through altered pronunciation. These combinations of linguistic resources, in fact, correspond quite closely to the features described and demonstrated in the participant's metalinguistic reflections on the ‘integrated' register (see Madsen 2011, 2013) and they are used to bring about similar values of hierarchical relations connected to institutional and educational aspects. The exaggerated polite, sophisticated and enthusiastic stylisations occur in our data in communicative contexts where norm transgressions and/or relations of authority of some kind are at play, and these situations involve either, directly or indirectly, teacher authorities or interviewers/researchers (we also find examples of these stylisations being used in narratives about prior experiences where norms were broken and verbal sanctions followed by authorities). A clear picture appears from the stylisation practices in the interactional sequences discussed here; a voice bringing about associations of conservative standard up-scale cultural values is inauthentically put on, and put on display in contexts where institutional inequalities are spotlighted. In this way, these interactional stylisations and their situated functions emphasise the dimension of symbolic power relations.

In this chapter, I have aimed to look beyond heteroglossia as such as the point of interest. Instead I have taken on board the notion of heteroglossia with its reference to diversity on the level of voicing as well as the levels of speech and language. Looking at contemporary sociolinguistic heteroglossia from a perspective of enregisterment enables us to relate situated stylisations as discussed above to current sociolinguistic processes on a larger scale. Recent Danish sociolinguistics has suggested that social class relations have relatively little contemporary sociolinguistic significance, and instead the discovery of new linguistic practices among youth in culturally and linguistically diverse environments has led to ethnicity being foregrounded. However 
if, in line with a linguistic ethnographic approach to sociolinguistics, we understand social class, ethnicity and other social categories as socio-cultural (and political) interpretations signified by certain cultural and linguistic practices rather than as existing bounded groups reflecting biological, place-related or socioeconomic facts (see also Rampton 2006, 2011, Brubaker 2004), interactional stylisations as the ones I have discussed here can alter this picture.

As an interpretive framework, social class includes various aspects of unequal lived relationships involving occupation and employment hierarchies, income and wealth, life-style, and finally cultural practices (including linguistic) arising from these (Bradley 1996: 45-46), whereas ethnicity involves the idea of territorial groups, nations states and processes of migration and conquests (Bradley 1996: 19-20). Class, then, can be seen as an awareness of a 'high' and 'low' societal stratification, and ethnicity as an awareness of territorial belongings involving 'inside' and 'outside' relations. The stylisation data I have discussed in this chapter supports the insights we have gained from our interview and essay data and shows that a sense of high/low stratification is indeed still relevant to contemporary Danish youth, only it is expressed and understood differently from traditional social class correlated speech styles.

\section{References}

Ag, A. 2010. Sprogbrug og identitetsarbejde hos senmoderne storbypiger. Københavnerstudier i Tosprogethed 53. København: Københavns Universitet.

Agha, A. 2003. The social life of cultural value. Language and Communication 23: 231-273.

Agha, A. 2005. Voice, footing, enregisterment. Journal of Linguistic Anthropology 15 (1): 38-59.

Agha, A. 2007. Language and social relations. Cambridge: Cambridge University Press. 
Andersen, N. M. 2010. Talesprog og sproglig polyfoni. TijdSchrift voor Skandinavistiek 31 (2): 323.

Bakhtin, M. 1981. The Dialogic Imagination. Austin TX: University of Texas Press.

Bakhtin, M. 1984. Problems of Dostoevsky’s Poetics. Minneapolis: University of Michigan Press.

Bailey, B. 2007. Heteroglossia and boundaries. In Bilingualism a Social Approach, ed. M. Heller, 257-276. London: Palgrave Macmillan.

Blackledge, A. and Creese, A. 2010. Multilingualism: A Critical Perspective. London, Continuum.

Blommaert, J. and B. Rampton. 2011. Language and Superdiversity. Diversities 13 (2): 1-22.

Bradley, H. 1996. Fractured identities: Changing patterns of inequality. London: Polity Press.

Brubaker, R. 2004. Ethnicity without groups. Cambridge: Harvard University Press.

Cambell-Kibler, K. 2012. Contenstation and Eregisterment in Ohio's Imagined Dialects. Journal of English Linguistics 40 (3): 281-305.

Coupland, N. 2007. Style. Language Variation and Identity. Cambridge: Cambridge University Press. 
Eckert, P. 2008. Variation and the indexical field. Journal of Sociolinguistics 12 (4): 453-476.

Frekko, S.E. 2009. "Normal” in Catalonia: Standard language, enregisterment and the imagination of a national public. Language in Society 38: 71-93.

Heller, M. 2007. Bilingualism as ideology and practice. In Bilingualism a Social Approach, ed. M. Heller, 1-22. London: Palgrave Macmillan.

Jaspers, J. 2010. Introduction - Society and language use. In Society and language use, eds. J. Jaspers, J-O Östman and J. Verschueren, 1-20. Amsterdam: John Benjamins.

Jaspers, J. 2011. Strange Bedfellows: Appropriations of a tainted urban dialect. Journal of Sociolinguistics 15 (4): 493-524.

Johnstone, B., J. Andrus and A. E. Danielsen. 2006. Mobility, Indexicality and the Enregisterment of "Pittsburghese". Journal of English Linguistics 34 (2): 77-104.

Johnstone, B. 2009. Pittsburghese shirts: commodification and the enregisterment of an urban dialect. American Speech 84 (2): 157-175.

Jørgensen, J.N., M. Karrebæk, L.M. Madsen and J.S. Møller. 2011. Polylanguaging in superdiversity. Diversities 13 (2): 23-38. 
Jørgensen, J. N. 2010. Languaging. Nine years of poly-lingual development of Turkish-Danish grade school students, vol. 1-2. Copenhagen Studies in Bilingualism, the Koge Series, vol. K15K16: University of Copenhagen.

Kristensen, K. 2003. Standard Danish, Copenhagen sociolects, and regional varieties in the 1900s. International Journal of the Sociology of Language 159: 29-44.

Kristiansen, T. 2009. The macro-level social meanings of late modern Danish accents. Acta Linguistica Hafniensia 41: 167-192.

Kristiansen, T. and J. N. Jørgensen. 2003. The Sociolinguistics of Danish. International Journal of the Sociology of Language 159: 1-7.

Maegaard, M. 2007. Udtalevariation og - forandring i kфbenhavnsk - en etnografisk unders $\phi$ gelse af sprogbrug, sociale kategorier og social praksis blandt unge på en københavnsk folkeskole.

København: Nordisk Forskningsinstitut.

Madsen, L. M. 2008. Fighters and Outsiders. Linguistic practices, social identities, and social relationships among urban youth in a martial arts club. Copenhagen: University of Copenhagen.

Madsen, L. M. 2011. Social status relations and enregisterment in contemporary Copenhagen. Working Papers in Urban Language and Literacies: 72.

Madsen, L. M. 2012. Late modern youth style in interaction. In Ethnic Styles of Speaking in European Metropolitan Areas, eds. F. Kern and M. Selting, 265-290. Amsterdam: John Benjamins.

Madsen, L. M. 2013. "High" and "Low" in urban Danish speech styles. Language in Society 42 (2): forthcoming. 
Madsen, L. M., J. N. Jørgensen and J. S. Møller. 2010. ”Street language” and ”Integrated": Language use and enregisterment among late modern urban girls. Copenhagen Studies in Bilingualism, vol. 55: 81-113. Copenhagen: University of Copenhagen.

Møller, J. S. 2009. Poly-lingual interaction across childhood, youth and adulthood. Copenhagen: University of Copenhagen.

Møller, J. M. and J. N. Jørgensen. 2011. Enregisterment among adolescents in superdiverse Copenhagen. In Language, Enregisterment and Attitudes, eds. J. S. Møller and J. N. Jørgensen, 99122. Copenhagen Studies in Bilingualism vol. 63: University of Copenhagen.

Pharao, N. and G. F. Hansen. 2006. Prosodic aspects of the Copenhagen Multiethnolect. Nordic prosody. Proceedings of the IXth Conference: 87-96. Lund: Peter Lang.

Pedersen, I.L. 2009. Processes of Standardization in Scandinavia. In Fra folkemål til multietnolek, eds. F. Gregersen and T. Kristiansen, 281-309. Oslo: Novus Forlag.

Pennycook, A. 2010. Language as a local practice. New York: Routledge.

Quist, P. 2005. Stilistiske praksisser i storbyens heterogene skole. En etnografisk og sociolingvistisk undersøgelse af sproglig variation. København: Nordisk forskningsinstitut.

Rampton, B. 1995. Crossing: Language and ethnicity among adolescents. London and New York: Longman. 
Rampton, B. 2006. Language in Late Modernity: Interaction in an urban school. Cambridge, UK: Cambridge University Press.

Rampton, B. 2009. Interaction ritual and not just artful performance in crossing and stylization. Language in Society 38 (2): 149-175.

Rampton, B. 2011. From 'multi-ethnic adolescent heteroglossia' to 'contemporary urban vernaculars'. Language and Communication 31 (4): 276-294.

Stæhr, A. 2010. Rappen reddede os. Et studie af senmoderne storbydrenges identitetsarbejde $i$ fritids- og skolemiljøer. København: Københavns Universitet.

Vertovec, S. 2010. Super-diversity and its implications. In Anthropology of Migration and Multiculturalism: New Directions, ed. S. Vertovec, 65-96. London: Routledge.

Wei, L. 2011. Moment analysis and translanguaging space: discursive construction of identities by multilingual Chinese youth in Britain. Journal of Pragmatics 43 (5): 1222-1235.

\section{Appendix}

Transcription key:

[overlap]

overlapping speech

LOUD louder volume than surrounding 
utterances

$\mathrm{XxX}$

uintelligible speech

(questionable)

parts I am uncertain about

((comment))

my comments

prolongation of preceding sound

$\uparrow$

local pitch raise

(.)

short pause

(0.6)

timed pause

Stress

stress

hhh

laughter breathe 